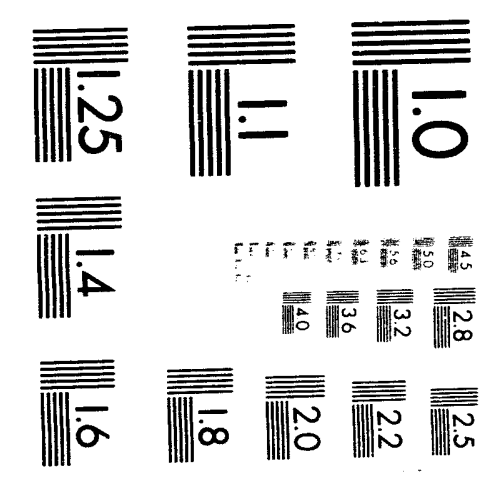



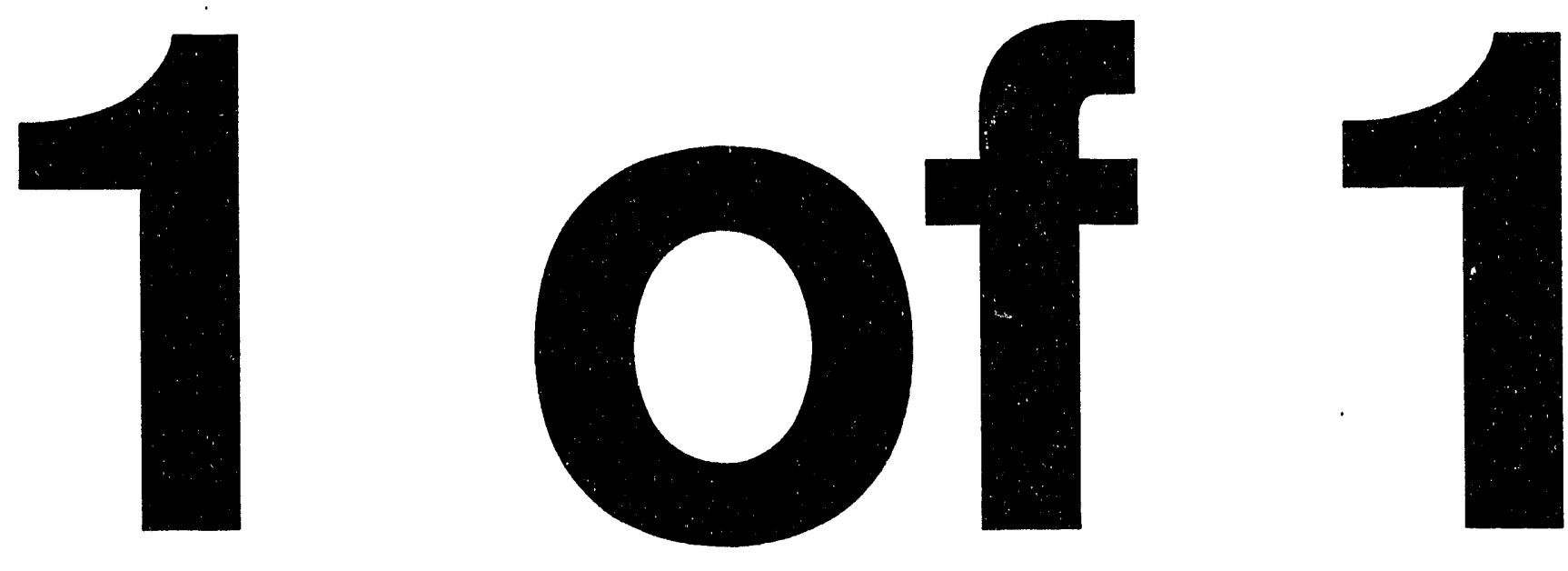


\title{
O-Shell Emission of Uranium in a High Temperature, Low Density Plasma
}

\author{
Kevin B. Fournier, A.L. Osterheld, W.H. Goldstein, \\ M. Finkenthal, C.P. Holmes, and H.W. Moos
}

ihis is an informal report intended primarily for internal or limited extemal distribution. The opinions and conclusions stated are those of the author and may or may not be those of the Laboratory.

Work performed under the auspices of the U.S. Department of Energy by the Lawrence Livermore National Laboratory under Contract W-7405-Eng-48. 


\section{DISCLAIMER}

This document was prepared as an account of work sponsored by an agency of the United States Government. Neither the United States Government nor the University of California nor any of their employees, makes any warranty, express or implied, or assumes any legal liability or responsibility for the accuracy, completeness, or usefulness of any information, apparatus, product, or process disclosed, or represents that its use would not infringe privately owned rights. Reference herein to any specific commercial products, process, or service by trade name, trademark, manufacturer, or otherwise, does not necessarily constitute or imply its endorsement, recommendation, or favoring by the United States Government or the University of California. The views and opinions of authors expressed herein do not necessarily state or reflect those of the United States Government or the University of California, and shall not be used for advertising or product endorsement purposes.

This report has been reproduced directly from the best available copy.

Available to DOE and DOE contractors from the Office of Scientific and Technical Information P.O. Box 62, Oak Ridge, TN 37831

Prices available from (615) 576-8401, FTS 626-8401

Available to the public from the National Technical Information Service

U.S. Department of Commerce 5285 Port Royal Rd., Springfield, VA 22161 


\title{
O-Shell Emission of Uranium in a High Temperature, Low Density Plasma
}

Kevin B. Fournier*, A. L. Osterheld, W. H. Goldstein

Lawrence Livermore National Laboratory, Livermore, California 94550

M. Finkenthal ${ }^{\dagger}$, C. P. Holmes, H. W. Moos

Department of Physics and Astronomy, The Johns Hopkins University, Baltimore, Maryland 21218

\begin{abstract}
$\underline{\text { Abstract }}$
We present models for the soft $X$ ray emission spectra of UXXIV, UXXV, UXXX, UXXXI and UXXXII under tokamak conditions. The spectra are calculated from collisional-radiative models and cover the 60 to $200 \AA$ range. A fully relativistic parametric potential code has been used for the $a b$ initio atomic structure calculations, and electron impact excitation rates have been computed in the distorted wave approximation. The ions considered here display a range of spectroscopic phenomena to be found in the O-shell of heavy elements, that can be compared with experimental observations. These include the configuration interaction between $5 s^{2} 5 p^{6} 5 d^{k-1} 5 f$ and $5 s^{2} 5 p^{5} 5 d^{k+1}$ in ions with $5 s^{2} 5 p^{6} 5 d^{k}$ ground configurations, represented by UXXIV $(\mathrm{k}=1)$; configuration interaction between $5 \mathrm{~s}^{2} 5 \mathrm{p}^{\mathrm{k}-1} 5 \mathrm{~d}$ and $5 \mathrm{~s}^{2} 5 \mathrm{p}^{\mathrm{k}+1}$ in ions with $5 \mathrm{~s}^{2} 5 \mathrm{p}^{\mathrm{k}}$ ground configurations, such as $\operatorname{UXXX}(\mathrm{k}=1)$; the unique system of satellite emission lines to the resonarit $5 \mathrm{~s}-5 \mathrm{p}$ transitions in UXXXII arising from highly metastable $4 \mathrm{f}^{13} 5 \mathrm{~s}^{2}$ levels; and the bright, isolated resonant lines associated with the closed shell UXXV and UXXXI systems.
\end{abstract}

*Permanent address, The Johns Hopkins University, Baltimore, Md.

'Permanent address, Racah Institute of Physics, The Hebrew University, Jerusalem, Israel.

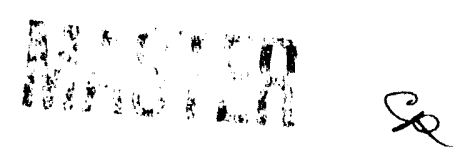




\section{Introduction}

In previous work, the XUV spectrum of uranium emitted from the high temperature, low density TEXT tokamak (Center for Fusion Research, University of Texas at Austin) plasma was analyzed in the 60-200 $\AA$ range.[1] The main emission features were identified with $n=5-n=5$ transitions within charge states having $5 p^{6} 5 \mathrm{~d}^{k}$ $(\mathrm{k}=1-10)$ ground configurations. The present work extends the theoretical analysis of the spectra to the UXXV (ground configuration $5 s^{2} 5 \mathrm{p}^{6}$ ) to UXXXII $\left(4 \mathrm{f}^{14} 5 \mathrm{~s}\right.$ ) ions emitting in the $65-200 \AA$ range. Beyond the general spectroscopic interest in line identifications and the opportunity to compare relativistic atomic structure calculations with experiment, the charge states under discussion here are important for their role in a soft $\mathrm{x}$-ray laser scherne based on neodymiumlike UXXXIII.[2]

The experiments done by Finkenthal et al. [1] involved using the laser blow-off method to introduce uranium atoms into hydrogen, deuterium and helium plasmas. The emission from the uranium ions was then recorded with a time-resolving, photometrically calibrated, grazing incidence spectrometer.[3] The time resolution of the experiment was $13.2 \mathrm{msec}$ and the spectral resolution was $0.7 \AA$.

Time resolved data gives some information as to whether medium or low charge states are responsible for the emission, since the transport in the plasma has been observed to be slow (centimeters per millisecond) and the characteristic times for spectral emission and the plasma lifetime are very long (tens or hundreds of milliseconds). Thus, different time frames show different charge states that are well isolated. If the data were time integrated, then one would not be certain which among close-lying components make up a spectral feature. However, by looking at the time history of the features in a given spectral region, one can assign the earlier structure to the lower charge states, and the later emission to ions that have burned through to a higher charge state.

This report presents and discusses theoretical predictions of wavelengths and line intensities of highly ionized uraniuin ions under tokamak plasma conditions. Another report will discuss the comparison between the theory and experimental data and make charge state identifications.

\section{Atomic Structure Calculations and Collisional Radiative Model}

$A b$ initio atomic structure calculations have been performed for UXXIV, XXV, $\mathrm{XXX}, \mathrm{XXXI}$ and XXXI (with ground states $5 \mathrm{p}^{6} 5 \mathrm{~d}, 5 \mathrm{p}^{6}, 5 \mathrm{~s}^{2} 5 \mathrm{p}, 5 \mathrm{~s}^{2}$ and $5 \mathrm{~s}$, respectively) using the parametric potential code RELAC, the relativistic version of MAPPAC.[4] For certain of these charge states, comparisons with level structure calculated by Cowan's Hartree-Fock computer code with relativistic corrections have also been made.[5] Using the HULLAC package developed at Hebrew University and Lawrence Livermore Laboratory, a collisional-radiative model has been constructed for each of the five charge states mentioned above. The package includes ANGLAR, which uses the graphical angular recoupling program NJGRAF to generate fine structure levels in a $j-j$-coupling scheme for a set of user-specified electron configurations, and computes the angular part of the Hamiltonian for each ion and the tensor operators for radiative and collisional transitions.[6] Next, RELAC generates wavefunctions and radiative transition probabilities. Finally, CROSS, a suite of three codes, is used to compute electron impact excitation cross sections and rate coefficients in the distorted wave approximation. [7] Data from these codes generates a collisional-radiative model which is solved in steady state for level populations and line emissivities. 
The output of the collisional-radiative model includes the level populations normalized to the ground state population for each energy level in an ion (marked $n_{i}$ in the tables below), and the relative intensity of transitions from any given level to any other level (marked I in the tables below). The models contain 343, 119, 140, 162 and 280 energy levels for UXXIV, XXV, XXX, XXXI and XXXII, respectively. The configurations used for these calculations will be listed below for each ion as it is described.

In the discussion below, for each ion there appears a list of the strong 5-5 transitions as predicted by RELAC. All intensities are computed with electron temperature, $T_{e}=1 \mathrm{keV}$, and electron density, $\mathrm{N}_{\mathrm{e}}=5.0 \times 10^{13} \mathrm{~cm}^{-3}$. These values are close to those measured in the tokamak plasma. At such low density, it is found that the populations of most doubly excited states are negligible. The calculations demonstrate the line intensities to be substantially insensitive to variations in $\mathrm{N}_{\mathrm{e}}$ of up to nearly a factor of 100. The temperature at which the calculations were done is substantially above the average excitation energy for the 5-5 transitions, which is in the range $\sim 50-300 \mathrm{eV}$, so that the simulated spectra are also relatively insensitive to variations in electron temperature. It was observed that cascades from $n=6$ and 7 levels had a negligible effect on the calculated spectra. At the densities considered in this experiment, the plasma is optically thin and under coronal conditions.

\section{Discussion of Uranium Ions}

\section{a. UXXIV}

This ion, isoelectronic to thulium, has the ground configuration $5 s^{2} 5 p^{6} 5$ d. Table I lists the brightest lines arising from the configurations $5 p^{6} 5 f$ and $5 p^{5} 5 d^{2}$. The configurations used to generate these lines were of the form $5 s^{2} 5 p^{6} 51(l=d, f), 5 s^{2} 5 p^{6} 6 l l$ $(l=s, p, d, f), 5 s^{2} 5 p^{5} 5 d 5 l(l=d, f), 5 s^{2} 5 p^{5} 5 d 6 l l(l=s, p, d), 5 s 5 p^{6} 5 d 5 l l(l=d, f)$ and $5 s^{5} p^{6} 5 d 6 l l$ $(1=s, p)$.

The wavelengths and intensities calculated here agree well with values calculated earlier using RELAC.[8] There are two active regions in the wavelength range from just short of $70 \AA$ to just long of $90 \AA$. The activity for this charge state centers around $67 \AA$ in the first band and $90 \AA$ in the second. The shorter wavelength band is due to transitions of the form $5 p^{6} 5 d-5 p^{5} 5 d^{2}$ with a $5 p_{1 / 2}$ hole in the upper state, and the longer wavelength band is due to similar transitions only with a $5 \mathrm{p}_{3 / 2}$ hole in the upper state. Note also that the longer wavelength transitions are very close to $5 p^{6} 5 d-5 p^{6} 5 f$ resonance transitions. This near-degeneracy is known to lead to a strong configuration interaction between $5 p^{5}{ }_{3 / 2} 5 d^{2}$ and the $5 p^{6} 5 f$ states, and two bands of emission centered near 70 and $90 \AA$, rather than three. $[1,8]$

The physical states of the $5 p^{6} 5 f$ orbital are listed in Table II. The states are named for the chief component $j$-j-coupled basis vector in their make-up. One can see from the table the large mixing of $5 p^{5} 5 d^{2}$ components into the two $5 p^{6} 5 f$ states. The ordered quartet of numbers in parenthesis represent the occupancies of the $5 p_{1 / 2,3 / 2}$ and $5 d_{3 / 2,5 / 2}$ relativistic orbitals in the various $J=5 / 2$ and $7 / 2$ levels (there is only one way to form $5 p^{6} 5 f$ and $5 p^{6} 6 f J=5 / 2$ and $7 / 2$ configurations). The list of components is not complete; only the most significant have been included. Thus the sum of percentages will not be 100.

As reported in Ref. 1, the transitions which originate with the excitation of a 
Table I. Transitions in thuliumlike UXXIV

TRANSITION $\quad I=n_{i} * A_{i j}\left[\mathrm{sec}^{-1}\right] \quad A_{i j}\left[\sec ^{-1}\right]$ wavelength $[\AA]$

\begin{tabular}{|l|l|l|l|}
\hline $5 \mathrm{p}^{6} \mathrm{dd}(\mathrm{J}=3 / 2)-5 \mathrm{p}^{6} 5 \mathrm{f}(\mathrm{J}=5 / 2)$ & $1.8 \mathrm{e}+05$ & $1.2 \mathrm{e}+12$ & 83.89 \\
$5 \mathrm{p}^{6} 5 \mathrm{~d}(\mathrm{~J}=5 / 2)-5 \mathrm{p}^{6} 5 \mathrm{f}(\mathrm{J}=7 / 2)$ & $2.0 \mathrm{e}+05$ & $8.1 \mathrm{e}+11$ & 90.64 \\
\hline \multicolumn{4}{|l|}{} \\
\hline $5 \mathrm{p}^{6} 5 \mathrm{~d}(\mathrm{~J}=3 / 2)-5 \mathrm{p}^{5} 5 \mathrm{~d}^{2}(\mathrm{~J}=3 / 2)$ & $1.4 \mathrm{e}+05$ & $3.3 \mathrm{e}+12$ & 66.69 \\
$5 \mathrm{p}^{6} 5 \mathrm{~d}(\mathrm{~J}=5 / 2)-5 \mathrm{p}^{5} 5 \mathrm{~d}^{2}(\mathrm{~J}=3 / 2)$ & $6.0 \mathrm{e}+04$ & $1.2 \mathrm{e}+12$ & 67.64 \\
$5 \mathrm{p}^{6} 5 \mathrm{~d}(\mathrm{~J}=5 / 2)-5 \mathrm{p}^{5} 5 \mathrm{~d}^{2}(\mathrm{~J}=7 / 2)$ & $1.7 \mathrm{e}+05$ & $2.1 \mathrm{e}+12$ & 67.64 \\
$5 \mathrm{p}^{6} 5 \mathrm{~d}(\mathrm{~J}=5 / 2)-5 \mathrm{p}^{5} 5 \mathrm{~d}^{2}(\mathrm{~J}=5 / 2)$ & $1.5 \mathrm{e}+05$ & $2.5 \mathrm{e}+12$ & 68.13 \\
$5 \mathrm{p}^{6} 5 \mathrm{~d}(\mathrm{~J}=3 / 2)-5 \mathrm{p}^{5} 5 \mathrm{~d}^{2}(\mathrm{~J}=1 / 2)$ & $4.2 \mathrm{e}+04$ & $1.8 \mathrm{e}+12$ & 68.23 \\
$5 \mathrm{p}^{6} 5 \mathrm{~d}(\mathrm{~J}=3 / 2)-5 \mathrm{p}^{5} 5 \mathrm{~d}^{2}(\mathrm{~J}=5 / 2)$ & $1.0 \mathrm{e}+05$ & $.1 \mathrm{e}+12$ & 72.26 \\
$5 \mathrm{p}^{6} 5 \mathrm{~d}(\mathrm{~J}=3 / 2)-5 \mathrm{p}^{5} 5 \mathrm{~d}^{2}(\mathrm{~J}=1 / 2)$ & $5.7 \mathrm{e}+04$ & $7.5 \mathrm{e}+11$ & 92.09 \\
$5 \mathrm{p}^{6} 5 \mathrm{~d}(\mathrm{~J}=5 / 2)-5 \mathrm{p}^{5} 5 \mathrm{~d}^{2}(\mathrm{~J}=5 / 2)$ & $1.5 \mathrm{e}+05$ & $8.0 \mathrm{e}+11$ & 93.38 \\
$5 \mathrm{p}^{6} 5 \mathrm{~d}(\mathrm{~J}=5 / 2)-5 \mathrm{p}^{5} 5 \mathrm{~d}^{2}(\mathrm{~J}=3 / 2)$ & $9.3 \mathrm{e}+04$ & $6.8 \mathrm{e}+11$ & 94.00 \\
$5 \mathrm{p}^{6} 5 \mathrm{~d}(\mathrm{~J}=3 / 2)-5 \mathrm{p}^{5} 5 \mathrm{~d}^{2}(\mathrm{~J}=3 / 2)$ & $9.6 \mathrm{e}+04$ & $5.5 \mathrm{e}+11$ & 96.08 \\
\hline
\end{tabular}

Table II. Mixing of $5 p^{6} 5 f$ and $5 p^{5} 1 / 2,3 / 25 d^{2}$ States for UXXIV

\begin{tabular}{|c|c|c|}
\hline & & physical state $5 p^{6} 5 \mathrm{f} J=5 / 2$ \\
\hline \multicolumn{2}{|c|}{ basis vectors } & \multirow{10}{*}{$\begin{array}{r}64.49 \\
1.16 \\
8.26 \\
3.68 \\
4.80 \\
7.20 \\
3.06 \\
4.21\end{array}$} \\
\hline \multicolumn{2}{|c|}{$(5 p-5 p+5 d-5 d+)$} & \\
\hline \multirow{8}{*}{$\begin{array}{l}5 p^{6} 5 f \\
5 p^{6} 6 f \\
5 p^{5} 5 d^{2} \\
5 p^{5} 5 d^{2} \\
5 p^{5} 5 d^{2} \\
5 p^{5} 5 d^{2} \\
5 p^{5} 5 d^{2} \\
5 p^{5} 5 d^{2} \\
\end{array}$} & \multirow{8}{*}{$\begin{array}{l}(1,4,2,0) \\
(2,3,1,1) \\
(2,3,1,1) \\
(2,3,1,1) \\
(2,3,1,1) \\
(2,3,0,2)\end{array}$} & \\
\hline & & \\
\hline & & \\
\hline & & \\
\hline & & \\
\hline & & \\
\hline & & \\
\hline & & \\
\hline \multirow{2}{*}{\multicolumn{2}{|c|}{ basis vectors }} & physical state $5 p^{6} 5 f \mathrm{~J}=7 / 2$ \\
\hline \multirow{2}{*}{\multicolumn{2}{|c|}{$\frac{\text { basis vectors }}{(5 p-5 p+5 d-5 d+)}$}} & \\
\hline & & \\
\hline \multicolumn{2}{|l|}{$5 p^{6} 5 f$} & 67.26 \\
\hline \multicolumn{2}{|l|}{$5 p^{6} 6 f$} & 1.10 \\
\hline $5 p^{5} 5 d^{2}$ & $(2,3,1,1)$ & 5.16 \\
\hline $5 p^{5} 5 d^{2}$ & $(1,4,1,1)$ & 5.75 \\
\hline $5 p^{5} 5 d^{2}$ & $(2,3,0,2)$ & 0.64 \\
\hline $5 p^{5} 5 d^{2}$ & $(2,3,0,2)$ & 19.36 \\
\hline
\end{tabular}


$5 \mathrm{~d}$ electron in uranium ions with $5 \mathrm{~d}^{\mathrm{k}}$ ground states generally fall into the range of 80 to $100 \AA$. It is expected that at the temperatures in the experiment described in Ref. 1 many of the charge states with $5 \mathrm{~d}^{\mathrm{k}}$ ground states will be present in the plasma, and, when this is the case, one can expect a very large number of lines in this spectral range. Owing to blending of strong spectral features from the different charge states considered here which lie very close together in wavelength, as well as the large number of features from lower charge states that also lie in this spectral range, it is expecteed to be very difficult to identify unambiguously in experimental spectra any features for this ion.

A synthetic spectrum for the collisional-radiative model of UXXIV in the 60 to $120 \AA$ range is shown in figure 1 .

\section{b. UXXV}

UXXV has the ground state configuration $5 s^{2} 5 p^{6}$. Configurations used in the calculation of this ion's spectrum were of the form $5 s^{2} 5 p^{5} 51 \quad(1=p, d, f), 5 s^{2} 5 p^{5} 61 \quad(1=s, p, d, f)$, $5 s 5 p^{6} 51(l=d, f), 5 s 5 p^{6} 61$ (l=s,p,d) and $5 s^{2} 5 p^{571}(1=s, p, d, f)$. This list is adequate for predicting line brightness at such low densities. The $5 \mathrm{~s}^{2} 5 \mathrm{p}^{5} 71$ configurations were included to account for configuration interaction and cascades as fully as possible. They had a negligible effect on the predicted values of transition wavelengths and intensities.

Table III. Transitions in erbiumlike UXXV

\begin{tabular}{|c|c|c|c|c|}
\hline \multirow[t]{2}{*}{ TRANSICION } & \multirow{2}{*}{$\mathrm{I}=\mathrm{n}_{\mathrm{i}}^{*} \mathrm{~A}_{\mathrm{ij}}\left[\mathrm{sec}^{-1}\right.$} & \multirow{2}{*}{$\mathrm{A}_{\mathrm{ij}}\left[\mathrm{sec}^{-1}\right]$} & \multicolumn{2}{|c|}{ wavelength $[\AA]$} \\
\hline & & & RELAC & $\mathrm{HF}$ \\
\hline $5 s^{2} 5 p^{6}-5 s^{2} 5 p^{5} 1 / 25 d(J=1)$ & $3.1 e+05$ & $1.7 e+12$ & 71.48 & 71.98 \\
\hline $5 s^{2} 5 p^{6}-5 s^{2} 5 p^{5} 3 / 25 d(J=1)$ & $4.1 e+05$ & $6.1 e+11$ & 101.86 & 100.99 \\
\hline $5 s^{2} 5 p^{5} 5 d(J=3)-5 s^{2} 5 p^{5} 5 f(J=4)$ & $\because .0 \mathrm{e}+05$ & $6.3 e+11$ & 89.91 & \\
\hline $5 s^{2} 5 p^{5} 5 d(\mathrm{~d}=4)-5 \mathrm{~s}^{2} 5 \mathrm{p}^{5} 5 \mathrm{f}(\mathrm{J}=5)$ & $1.1 \mathrm{e}+05$ & $7.2 \mathrm{e}+11$ & 95.28 & \\
\hline
\end{tabular}

This closed-shell ion gives rise to two strong, isolated 5p-5d transitions. Since these may be apparent in experimental spectra, it is especially important to accurately predict their wavelengths. Also, the $5 \mathrm{~d}-5 \mathrm{f}$ transitions in this ion do not mix with the 5p3/2$5 \mathrm{~d}$, as they do in lower charge states, since the emitting configurations are of opposite parity.

Table III shows wavelength values for the 5p-5d lines both from RELAC and from Hartree-Fock (HF) calculations performed with Cowan's code.[5] The values reported here for the resonance transition wavelengths calculated by both codes agree quite well. However, this degree of agreement is obtained only after dropping, ad hoc, the configuration interaction predicted by RELAC between the ground state and ${ }^{1} \mathrm{~S}_{0}$ components of the $5 \mathrm{p}^{5} 6 \mathrm{p}$ configurations. In the Hartree-Fock treatment, this interaction automatically vanishes since it involves configurations of the same symmetry differing in only one orbital. With the $5 p^{6}-5 p^{5} 6 p\left({ }^{1} S_{0}\right)$ interaction included, RELAC predicts a mixing of about $4 \%$, and wavelengths of 67.48 and $93.73 \AA$ for the $5 p-5 d$ transitions.

We have no firm justification for neglecting the ground state configuration interaction, but there two obvious possible sources for its overestimation in the 
parametric potential model. The first possibility is that the numerical accuracy of the present calculation is not sufficient in this case, where many integrals, representing interactions with each core orbital from $1 \mathrm{~s}$ through $5 \mathrm{~s}$, are being added and subtracted to obtain what should presumably be a very small number. The second possibility is that the wavelength shift induced by the $5 \mathrm{p}^{5} 6 \mathrm{p}$ interaction is cancelled by interactions with all other ${ }^{1} \mathrm{~S}_{0}$ states, conceivably up to and including the continuum. Neither of these possibilities occur in the Hartree-Fock model, since the one-electron interaction is identically zero. Of course, a third possibility - that the parametric potential result is more accurate - cannot be dismissed until evidence is adduced to the contrary. We are currently pursuing all three possibilites.

A synthetic spectrum for the collisional-radiative model of UXXV in the 60 to $130 \AA$ range is shown in figure 2 .

Table IV. Physical States in UXXV

\begin{tabular}{|c|c|}
\hline physical state: & $x 5 p^{6} J=0$ \\
\hline basis vectors & \multirow[b]{3}{*}{100.0} \\
\hline $5 \mathrm{~s}, 5 \mathrm{p}-, 5 \mathrm{p}+, \ldots, 6 \mathrm{p}-, 6 \mathrm{p}+$ & \\
\hline$x 5 p^{6}$ & \\
\hline
\end{tabular}

\begin{tabular}{|c|c|c|}
\hline physical state: & $5 p^{5} 3 / 25 d J=1$ & $5 p^{5} 1 / 25 d J=1$ \\
\hline \multicolumn{3}{|l|}{ basis vectors } \\
\hline $5 p-, 5 p+, 5 d-, 5 d+\ldots 6 d-, 6 d+$ & & \\
\hline $5 p^{5} 5 d \quad(2,3,1,0)$ & 7.40 & 0.12 \\
\hline$(1,4,1,0)$ & 4.81 & 93.38 \\
\hline $5 p^{5} 5 d \quad(2,3,0,1)$ & 85.86 & 4.50 \\
\hline $5 p^{5} 6 d \quad(1,4, \ldots, 1,0)$ & 0.02 & 1.68 \\
\hline $5 p^{5} 6 d \quad(2,3, \ldots, 0,1)$ & 1.74 & 0.29 \\
\hline
\end{tabular}

\begin{tabular}{|l|c|}
\hline physical state: & $5 \mathrm{p}^{5} 3 / 25 \mathrm{f} \mathrm{J}=4$ \\
\hline basis vectors & \\
\hline $5 \mathrm{p}-, 5 \mathrm{p}+, 5 \mathrm{~d}-, 5 \mathrm{~d}+, 5 \mathrm{f}-, 5 \mathrm{f}+, \ldots, 6 \mathrm{f}-, 6 \mathrm{f}+$ & 96.04 \\
\hline $5 \mathrm{p}^{5} 5 \mathrm{f} \quad(2,3,0,0,1,0)$ & 0.37 \\
$5 \mathrm{p}^{5} 5 \mathrm{f} \quad(2,3,0,0,0,1)$ & 0.05 \\
$5 \mathrm{p}^{5} 5 \mathrm{f} \quad(1,4,0,0,0,1)$ & 3.53 \\
$5 \mathrm{p}^{5} 6 \mathrm{f} \quad(2,3,0,0, \ldots, 1,0)$ &
\end{tabular}

\begin{tabular}{|c|c|}
\hline physical state: & $5 p^{5} 3 / 25 f J=5$ \\
\hline basis vectors & \multirow{4}{*}{$\begin{array}{r}96.54 \\
3.46\end{array}$} \\
\hline $5 p-, 5 p+, 5 d-, 5 d+, 5 f-5 f+, \ldots, 6 f-, 6 f+$ & \\
\hline $5 p^{5} 5 f \quad(2,3,0,0,0,1)$ & \\
\hline $5 p^{5} 6 f \quad(2,3,0,0, \ldots, 0,1)$ & \\
\hline
\end{tabular}




\section{c. UXXX}

UXXX has a $5 s^{2} 5 p$ ground state configuration. The configurations used in the calculation reported upon here are $5 \mathrm{~s}^{2} 51(1=\mathrm{p}, \mathrm{d}, \mathrm{f}), 5 \mathrm{~s}^{2} 61(\mathrm{l}=\mathrm{s}, \mathrm{p}, \mathrm{d}, \mathrm{f}), 5 \mathrm{~s} 5 \mathrm{p} 51(\mathrm{l}=\mathrm{p}, \mathrm{d}, \mathrm{f})$ and $5 \mathrm{~s} 5 \mathrm{p} 6 \mathrm{l}(\mathrm{l}=\mathrm{s}, \mathrm{p}, \mathrm{d}, \mathrm{f})$. This ion possesses a simple ground state which will have strong transitions of the form $5 \mathrm{p}-5 \mathrm{~d}$. In the model, a series of relatively bright $5 \mathrm{~s}-5 \mathrm{p}$ lines are also predicted. These are listed below in Table V. These 5s-5p transitions are well separated in wavelength from both of the $5 \mathrm{p}-5 \mathrm{~d}$ lines.

Note that in this ion, as in all ions with $5 \mathrm{~s}^{2} 5 \mathrm{p}^{\mathrm{k}}$ ground states, the $5 \mathrm{~s}^{2} 5 \mathrm{~d}$ configuration can interact with the $5 \mathrm{~s} 5 \mathrm{p}^{2}$ configuration. The physical states calculated by RELAC show the $5 \mathrm{~s}^{2} 5 \mathrm{~d}(\mathrm{~J}=3 / 2)$ state to be approximately $95 \%$ pure while the $5 \mathrm{~s}^{2} 5 \mathrm{~d}$ $(\mathrm{J}=5 / 2)$ state is only $80 \%$ pure with the rest of its amplitude being made up of the $5 \mathrm{~s} 5 \mathrm{p}^{2}$ configuration. This interaction, analogous to the $5 \mathrm{p}^{6} 5 \mathrm{~d}^{\mathrm{k}-1} 5 \mathrm{f}-\left(5 \mathrm{p}^{5}\right)_{3 / 2} 5 \mathrm{~d}^{\mathrm{k}+1}$ interaction in lower charge states, explains the relative quenching of the $5 s^{2} 5 p(J=3 / 2)-5 s^{2} 5 d(J=5 / 2)$ transitions.

Table V. Transitions in europiumlike UXXX

\begin{tabular}{|c|c|c|c|c|}
\hline TRANSITION & \multicolumn{2}{|c|}{$I=n_{i}^{*} A_{i j}\left[\sec ^{-1}\right] \quad A_{i j}\left[\sec ^{-1}\right]$} & \multicolumn{2}{|c|}{ wavelength $[\AA]$} \\
\hline $\begin{array}{l}5 \mathrm{~s}^{2} 5 \mathrm{p}(\mathrm{J}=1 / 2)-5 \mathrm{~s}^{2} 5 \mathrm{~d}(\mathrm{~J}=3 / 2) \\
5 \mathrm{~s}^{2} 5 \mathrm{p}(\mathrm{J}=3 / 2)-5 \mathrm{~s}^{2} 5 \mathrm{~d}(\mathrm{~J}=5 / 2)\end{array}$ & $\begin{array}{l}1.3 e+05 \\
1.2 e+04\end{array}$ & $\begin{array}{l}1.2 \mathrm{e}+12 \\
1.8 \mathrm{e}+11\end{array}$ & $\begin{array}{r}68.12 \\
101.99 \\
\end{array}$ & $\begin{array}{c}68.28 \\
104.45 \\
\end{array}$ \\
\hline $\begin{array}{l}5 \mathrm{~s}^{2} 5 \mathrm{p}(\mathrm{J}=1 / 2)-5 \mathrm{~s} 5 \mathrm{p}^{2}(\mathrm{~J}=1 / 2) \\
\left.5 \mathrm{~s}^{2} 5 \mathrm{p}(\mathrm{J}=1 / 2)-5 \mathrm{~s} 5 \mathrm{p}^{2}(\mathrm{~J}=\mathrm{j})^{\prime}\right) \\
5 \mathrm{~s}^{2} 5 \mathrm{p}(\mathrm{J}=1 / 2)-5 \mathrm{~s} 5 \mathrm{p}^{2}(\mathrm{~J}=1 / 2) \\
5 \mathrm{~s}^{2} 5 \mathrm{p}(\mathrm{J}=3 / 2)-5 \mathrm{~s}^{2} \mathrm{p}^{2}(\mathrm{~J}=5 / 2)\end{array}$ & $\begin{array}{l}9.3 e+04 \\
1.2 e+05 \\
5.6 e+04 \\
1.4 e+04\end{array}$ & $\begin{array}{l}7.0 \mathrm{e}+11 \\
3.8 \mathrm{e}+11 \\
2.8 \mathrm{e}+10 \\
1.4 \mathrm{e}+10\end{array}$ & $\begin{array}{r}85.37 \\
86.38 \\
182.45 \\
192.22\end{array}$ & $\begin{array}{l}84.69 \\
85.26\end{array}$ \\
\hline
\end{tabular}

The remaining $5 p_{1 / 2}-5 d_{3 / 2}$ line predicted at $\sim 68 \AA$ is unlikely to be identifiable seperately from the p-d emission cluster centered at $\sim 70 \AA$, and arising from lower charge states. $[1,8]$

In the 80 to $90 \AA$ spectral region a similar difficulty with the identification of lines occurs because of the abundance of transitions within the charge states UXV to UXXIII. These are transitions of the form $5 \mathrm{p}^{6} 5 \mathrm{~d}^{\mathrm{k}}-\left(5 \mathrm{p}^{5}\right)_{3 / 2} 5 \mathrm{~d}^{\mathrm{k}+1}$, previously assigned to a clump of emission features near $88 \AA$.[1] The identification of UXXX features is further hampered by strong UXXXI lines, and an unusual series of UXXXII satellites, discussed below, in the same spectral range. Hence identification of UXXX lines is problematic.

Synthetic spectra for the UXXX collisional-radiative model are shown in figure 3.

\section{d. UXXXI}

Level structure and transition rates for UXXXI were calculated for both singly and doubly excited configurations by moving electrons from both $n=4$ and $n=5$ orbitals. The configurations used in the calculation include $4 \mathrm{f}^{14} 5 \mathrm{~s} 51$ (l=s,p,d,f), $4 \mathrm{f}^{14} 5 \mathrm{p} 5 \mathrm{l}(\mathrm{l}=\mathrm{p}, \mathrm{d})$, $4 \mathrm{f}^{14} 5 \mathrm{~s} 61(1=\mathrm{s}, \mathrm{p}, \mathrm{d}, \mathrm{f}), 4 \mathrm{f}^{13} 5 \mathrm{~s}^{2} 5 \mathrm{l}(\mathrm{l}=\mathrm{p}, \mathrm{d}, \mathrm{f})$ and $4 \mathrm{f}^{13} 5 \mathrm{~s}^{2} \mathrm{p}^{2}$. UXXXI has a ground state of $5 \mathrm{~s}^{2}$, and, thus, one can expect transitions originating from the $5 \mathrm{~s} 5 \mathrm{p}(\mathrm{J}=1)$ levels to be the strongest. These are displayed in Table VI. 
Table VI. Transitions in samariumlike UXXXI

\begin{tabular}{|l|l|l|l|l|}
\multicolumn{1}{c}{ TRANSITION } & $\mathrm{I}=\mathrm{n}_{\mathrm{i}}{ }^{*} \mathrm{~A}_{\mathrm{ij}}\left[\mathrm{sec}^{-1}\right] \mathrm{A}_{\mathrm{ij}}\left[\mathrm{sec}^{-1}\right]$ & \multicolumn{3}{c|}{ wavelength $[\AA]$} \\
& \multicolumn{2}{c|}{ RELAC } \\
\hline $5 \mathrm{~s}^{2}-5 \mathrm{~s}^{2} \mathrm{p}_{3 / 2}(\mathrm{~J}=1)$ & $2.5 \mathrm{e}+05$ & $6.0 \mathrm{e}+11$ & 85.99 & 85.16 \\
$5 \mathrm{~s}^{2}-5 \mathrm{~s}_{\mathrm{p}} \mathrm{p}_{1 / 2}(\mathrm{~J}=1)$ & $1.4 \mathrm{e}+05$ & $1.7 \mathrm{e}+10$ & 187.93 & 193.48 \\
\hline
\end{tabular}

Owing to the simplicity of the ground state configuration, only two strong resonance transitions dominate the spectrum, and may be discernible in experiments. These transitions originate from the states $5 \mathrm{~s} 5 \mathrm{p}(1 / 2,3 / 2) 1$ and $(1 / 2,1 / 2) 1$, respectively. According to RELAC these states are almost $99 \%$ pure in the $j$-j-basis.

Table VII. Physical States in UXXXI

\begin{tabular}{|c|c|c|c|}
\hline \multicolumn{2}{|c|}{$\begin{array}{l}\text { physical states } \\
\text { basis vectors } \\
4 \mathrm{f}-4 \mathrm{f}+5 \mathrm{~s}+5 \mathrm{p}-5 \mathrm{p}+\ldots 6 \mathrm{p}-6 \mathrm{p}+\end{array}$} & $5 \mathrm{~s} 5 \mathrm{p}_{1 / 2} \mathrm{~J}=1$ & $5 s 5 p_{3 / 2} J=1$ \\
\hline \multicolumn{2}{|c|}{ basis vectors } & \multirow[b]{3}{*}{98.80} & \multirow[b]{3}{*}{0.92} \\
\hline \multicolumn{2}{|c|}{$4 f-4 f+5 s+5 p-5 p+\ldots 6 p-6 p+$} & & \\
\hline $5 s 5 p$ & $(6,8,1,1,0)$ & & \\
\hline $5 s 5 p$ & $(6,8,1,0,1)$ & 0.96 & 98.53 \\
\hline $5 s 6 p$ & $(6,8,1, \ldots, 1,0)$ & 0.11 & 0.01 \\
\hline $5 s 6 p$ & $(6,8,1, \ldots, 0,1)$ & 0.00 & 0.14 \\
\hline
\end{tabular}
figure 4 .

Synthetic spectra for the collisional-radiative model of UXXXI are shown in

\section{e. UXXXII}

This ion has the deceptively simple ground state $4 \mathrm{f}^{14} 5 \mathrm{~s}$. For the purpose of calculating the ion's structure, both singly and doubly excited configurations formed by moving electrons from both the $n=4$ and $n=5$ orbitals were considered. The configurations used in the calculation are $4 \mathrm{f}^{14} 5 \mathrm{l}(\mathrm{l}=\mathrm{s}, \mathrm{p}, \mathrm{d}, \mathrm{f}), 4 \mathrm{f}^{14} 6 \mathrm{l}(\mathrm{l}=\mathrm{s}, \mathrm{p}, \mathrm{d}, \mathrm{f}), 4 \mathrm{f}^{13} 5 \mathrm{~s} 51(\mathrm{l}=\mathrm{s}, \mathrm{p}, \mathrm{d}, \mathrm{f}), 4 \mathrm{f}^{13} 5 \mathrm{p}^{2}$ and $4 f^{135}$ s6l $(l=s, p, d, f)$.

But despite its simplicity, UXXXII, isoelectronic to promethium, is interesting owing to a pair of metastable $4 \mathrm{f}^{13} 5 \mathrm{~s}^{2}$ levels about $150 \mathrm{eV}$ above the ground state which can serve as the source of many bright lines. These levels are formed by either collisional excitation of a $4 \mathrm{f}$ electron of the UXXXII ground state or ionization of a $4 \mathrm{f}$ electron in the UXXXI ground state. In the collisional-radiative models considered here, only the excitation channels were included. Because the ground state has $j=1 / 2$, while the $4 f^{13} 5 s^{2}$ has only $5 / 2$ and $7 / 2$ components and is calculated to be over $99 \%$ pure, these states do not decay radiatively to the ground state or to a $4 f^{14} 5 p$ state. Hence, there will exist a whole selies of transitions of the form $4 \mathrm{f}^{13} 5 \mathrm{~s}^{2}-4 \mathrm{f}^{13} 5 \mathrm{~s} 5 \mathrm{p}$ emitted as satellites to the resonance $4 \mathrm{f}^{14} 5 \mathrm{~s}-4 \mathrm{f}^{14} 5 \mathrm{p}$ lines. The satellites and resonance lines are listed below in Table VIII. 
Table VIII. Transitions in promethiumlike UXXXII

\begin{tabular}{|c|c|c|c|}
\hline TRANSITION & $\mathrm{I}=\mathrm{n}_{\mathrm{j}}{ }^{*} \mathrm{~A}_{\mathrm{ij}}\left[\mathrm{sec}^{-1}\right]$ & $A_{i j}\left[\sec ^{-i}\right]$ & wavelength $[\AA]$ \\
\hline $\begin{array}{l}4 f^{14} 5 s(J=1 / 2)-4 f^{14} 5 p(J=3 / 2) \\
4 f^{14} 5 s(J=1 / 2)-4 f^{14} 5 p(J=1 / 2)\end{array}$ & $\begin{array}{l}1.2 \mathrm{e}+05 \\
9.5 \mathrm{e}+04\end{array}$ & $\begin{array}{l}4.0 \mathrm{e}+11 \\
4.9 \mathrm{e}+10\end{array}$ & $\begin{array}{l}86.06 \\
174.11\end{array}$ \\
\hline $\begin{array}{l}4 \mathrm{f}^{13} 5 \mathrm{~s}^{2}(\mathrm{~J}=7 / 2)-4 \mathrm{f}^{13} 5 \mathrm{~s} 5 \mathrm{p}(\mathrm{J}=7 / 2) \\
4 \mathrm{f}^{13} 5 \mathrm{~s}^{2}(\mathrm{~J}=7 / 2)-4 \mathrm{f}^{13} 5 \mathrm{~s} 5 \mathrm{p}(\mathrm{J}=5 / 2) \\
4 \mathrm{f}^{13} 5 \mathrm{~s}^{2}(\mathrm{~J}=7 / 2)-4 \mathrm{f}^{13} 5 \mathrm{~s} 5 \mathrm{p}(\mathrm{J}=9 / 2) \\
4 \mathrm{f}^{13} 5 \mathrm{~s}^{2}(\mathrm{~J}=5 / 2)-4 \mathrm{f}^{13} 5 \mathrm{~s} 5 \mathrm{p}(\mathrm{J}=7 / 2) \\
4 \mathrm{f}^{13} 5 \mathrm{~s}^{2}(\mathrm{~J}=7 / 2)-4 \mathrm{f}^{13} 5 \mathrm{~s} 5 \mathrm{p}(\mathrm{J}=5 / 2) \\
4 \mathrm{f}^{13} 5 \mathrm{~s}^{2}(\mathrm{~J}=7 / 2)-4 \mathrm{f}^{13} 5 \mathrm{~s} 5 \mathrm{p}(\mathrm{J}=9 / 2) \\
4 \mathrm{f}^{13} 5 \mathrm{~s}^{2}(\mathrm{~J}=7 / 2)-4 \mathrm{f}^{13} 5 \mathrm{~s} 5 \mathrm{p}(\mathrm{J}=5 / 2) \\
4 \mathrm{f}^{13} 5 \mathrm{~s}^{2}(\mathrm{~J}=7 / 2)-4 \mathrm{f}^{13} 5 \mathrm{~s} 5 \mathrm{p}(\mathrm{J}=9 / 2) \\
4 \mathrm{f}^{13} 5 \mathrm{~s}^{2}(\mathrm{~J}=7 / 2)-4 \mathrm{f}^{13} 5 \mathrm{~s} 5 \mathrm{p}(\mathrm{J}=7 / 2)\end{array}$ & \begin{tabular}{|l|}
$4.1 \mathrm{e}+05$ \\
$5.5 \mathrm{e}+04$ \\
$3.1 \mathrm{e}+05$ \\
$2.0 \mathrm{e}+05$ \\
$2.6 \mathrm{e}+05$ \\
$2.4 \mathrm{e}+05$ \\
$1.6 \mathrm{e}+05$ \\
$2.7 \mathrm{e}+05$ \\
$1.8 \mathrm{e}+05$ \\
\end{tabular} & $\begin{array}{l}6.3 e+11 \\
1.0 e+11 \\
3.6 e+11 \\
6.1 e+11 \\
5.0 e+11 \\
2.6 e+11 \\
1.8 e+10 \\
1.7 e+10 \\
1.5 e+10 \\
\end{array}$ & $\begin{array}{l}82.75 \\
83.39 \\
83.72 \\
83.89 \\
84.21 \\
84.45 \\
184.91 \\
186.18 \\
186.72 \\
\end{array}$ \\
\hline
\end{tabular}

The collisional-radiative models constructed for this charge state reveal that the transitions to the metastable levels, that is, the satellite lines, are, in many cases, brighter than the resonance transitions. The reason for the anomalous brightness of these lines is not hard to understand. First, the $4 \mathrm{f}^{13} 5 \mathrm{~s}^{2}$ are roughly in LTE with respect to the ground state, since they are coupled through $4 \mathrm{f}-5 \mathrm{~s}$ collisional transitions, and have no allowed radiative decay modes. (They do decay through M2 transitions, which are included in the model.) Then, the fact that the plasma is at a temperature of $i \mathrm{keV}$ and the $\Delta \mathrm{E}$ for these levels with respect to the ground state is $0.15 \mathrm{keV}$ means that the boltzmann factor is nearly unity. Finally, since the statistical weight of the $4 \mathrm{f}^{13} 5 \mathrm{~s}^{2}(\mathrm{~J}=7 / 2)$ level is 8 as opposed to 2 for the true ground state, the ratio of the population for the $4 \mathrm{f}^{13} 5 \mathrm{~s}^{2}$ level to that of the $4 \mathrm{f}^{14} 5 \mathrm{~s}$ level is $4 \times \exp (-.15)=3.4$. On the other hand, the oscillator strength for the $5 s-5 p$ transition is nearly independent of the occupancy of the $4 \mathrm{f}$ and $5 \mathrm{~s}$ orbitals.

Thus, we expect the sateilite lines to be 3 to 4 times stronger than the resonance lines, on the basis of relative statistical weight alone. Populations in collisional-radiative equilibrium of the low-lying levels of UXXXII are shown in Table IX.

Table IX. Populations relative to the ground state (A) and to LTE (B) in UXXXII level A B

\begin{tabular}{|l|l|l|l|}
\hline 1 & $4 \mathrm{f}^{14} 5 \mathrm{~s} J=1 / 2$ & $1.000 \mathrm{E}+00$ & $1.00 \mathrm{E}+00$ \\
2 & $4 \mathrm{f}^{14} 5 \mathrm{p} J=1 / 2$ & $0.197 \mathrm{E}-05$ & $0.21 \mathrm{E}-05$ \\
3 & $4 \mathrm{f}^{14} 5 \mathrm{p} J=3 / 2$ & $0.302 \mathrm{E}-06$ & $0.17 \mathrm{E}-06$ \\
4 & $4 \mathrm{f}^{13} 5 \mathrm{~s}^{2} \mathrm{~J}=7 / 2$ & $0.536 \mathrm{E}+01$ & $0.16 \mathrm{E}+01$ \\
5 & $4 \mathrm{f}^{13} 5 \mathrm{~s}^{2} \mathrm{~J}=5 / 2$ & $0.194 \mathrm{E}+01$ & $0.74 \mathrm{E}+00$ \\
\hline
\end{tabular}

figure 5 .

Synthetic spectra for the collisional-radiative model of UXXXII are shown in 


\section{Conclusions}

In conclusion, $a b$ initio relativistic energy level calculations and collisionalradiative line intensities have been computed for a selection of charga states between UXXIV and UXXXI. These calculations are useful in understanding the resonant emission of these ions in the $60-200 \AA$ range from a tokamak plasma, though the lack of isoelectronic data and the relatively low spectral resolution of existing experimental data are expected to make unambiguous identification of individual transitions very difficult.

The ions considered here display a range of spectroscopic phenomena to be found in the $\mathrm{O}$-shell of heavy elements, that can be compared with experimental observations. These include the configuration interaction between $5 s^{2} 5 \mathrm{p}^{6} 5 \mathrm{~d}^{\mathrm{k}-1} 5 \mathrm{f}$ and $5 \mathrm{~s}^{2} 5 \mathrm{p}^{5} 5 \mathrm{~d}^{\mathrm{k}+1}$ in ions with $5 \mathrm{~s}^{2} 5 \mathrm{p}^{6} 5 \mathrm{~d}^{\mathrm{k}}$ ground configurations, represented by UXXIV $(\mathrm{k}=1)$; configuration interaction between $5 s^{2} 5 \mathrm{p}^{\mathrm{k}-1} 5 \mathrm{~d}$ and $5 \mathrm{~s}^{2} 5 \mathrm{p}^{\mathrm{k}+1}$ in ions with $5 \mathrm{~s}^{2} 5 \mathrm{p}^{\mathrm{k}}$ ground configurations, such as UXXX $(\mathrm{k}=1)$; the unique system of satellite emission lines to the resonant $5 \mathrm{~s}-5 \mathrm{p}$ transitions in UXXXII arising from highly metastable $4 \mathrm{f}^{13} 5 \mathrm{~s}^{2}$ levels; and the bright, isolated resonant lines associated with the closed shell UXXV and UXXXI systems.

In addition, comparisons have been made between the energy level calculations done with a parametric potential model and calculations using a Hartree-Fock code, including relativistic corrections. The agreement between the two sets of calculations is generally quite good though, for UXXV, a discrepency was found in the amo nt of configuration interaction predicted between the $5 p^{6}$ and $5 p^{5} 6{ }^{1} S_{0}$ states. This leads to a large difference in the predicted wavelengths of $5 \mathrm{p}-5 \mathrm{~d}$ transitions that is eliminated only when the configuration interaction is eliminated, ad hoc, from the parametric potential calculation. 


\section{REFERENCES}

[1] M. Finkenthal, S. Lippmann, H. W. Moos, P. Mandelbaum, and the TEXT Group, Phys. Rev. A 39, 3717 (1989).

[2] P. L. Hagelstein and S. Dalhed, Phys. Rev. A 37, 1358 (1988).

[3] W. L Hodge, B. C. Stratton, and H. W. Moos, Rev. Sci. Instrum. 55, 6(1984).

[4] M. Klapisch, Comput. Phys. Commun. 2, 269 (1971); M. Klapisch, J. L. Schwob, B. S. Fraenkel, and J. Oreg, J. Opt. Soc. Am. 67, 148 (1977).

[5] V. Kaufman, private communication. See also for details about the Hartree Fock method and codes R. Cowan. The Theory of Atomic Structure and Spectra, Univ. of California Press, 1981.

[6] A. Bar-Shalom and M. Klapisch, Comput. Phys. Commun. 50, 375 (1988).

[7] A. Bar-Shalom, M. Klapisch, and J. C. 㓅, Phys. Rev. A 38, 1773 (1988).

[8] M. Finkenthal, S. Lippmann, L.K. Huang, A. Zwicker, H.W. Moos, W.H. Goldstein and A.L. Osterheld, Phys. Rev. A 45, 5846 (1992). 


\section{Figure Captions}

Figure 1. Synthetic collisional-radiative spectra of UXXIV in the 60 to $120 \AA$ range for $\mathrm{T}_{\mathrm{e}}=1 \mathrm{keV}$ and $\mathrm{N}_{\mathrm{e}}=5.0 \times 10^{13} \mathrm{~cm}^{-3}$, conditions similar to those found in the TEXT tokamak.

Figure 2. Synthetic collisional-radiative spectra of UXXV in the 60 to $130 \AA$ range for $\mathrm{T}_{\mathrm{e}}=1 \mathrm{keV}$ and $\mathrm{N}_{\mathrm{e}}=5.0 \times 10^{13} \mathrm{~cm}^{-3}$.

Figure 3. Synthetic collisional-radiative spectra of UXXX in the (a) 60 to $110 \AA$ range, and (b) 160 to $200 \AA$ range, for $\mathrm{T}_{\mathrm{e}}=1 \mathrm{keV}$ andN $\mathrm{e}_{\mathrm{e}}=5.0 \times 10^{13} \mathrm{~cm}^{-3}$.

Figure 4. Synthetic collisional-radiative spectra for UXXXI in the (a) 60 to $110 \AA$ range and (b) 160 to $200 \AA$ range, for $\mathrm{T}_{\mathrm{e}}=1 \mathrm{keV}$ andN $\mathrm{e}_{\mathrm{e}}=5.0 \times 10^{13} \mathrm{~cm}^{-3}$.

Figure 5. Synthetic collisional-radiative spectra for UXXXI in the (a) 60 to $110 \AA$ range and (b) 160 to $200 \AA$ range, for $T_{e}=1 \mathrm{keV}$ andN $\mathrm{e}_{\mathrm{e}}=5.0 \times 10^{13} \mathrm{~cm}^{-3}$. 


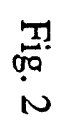

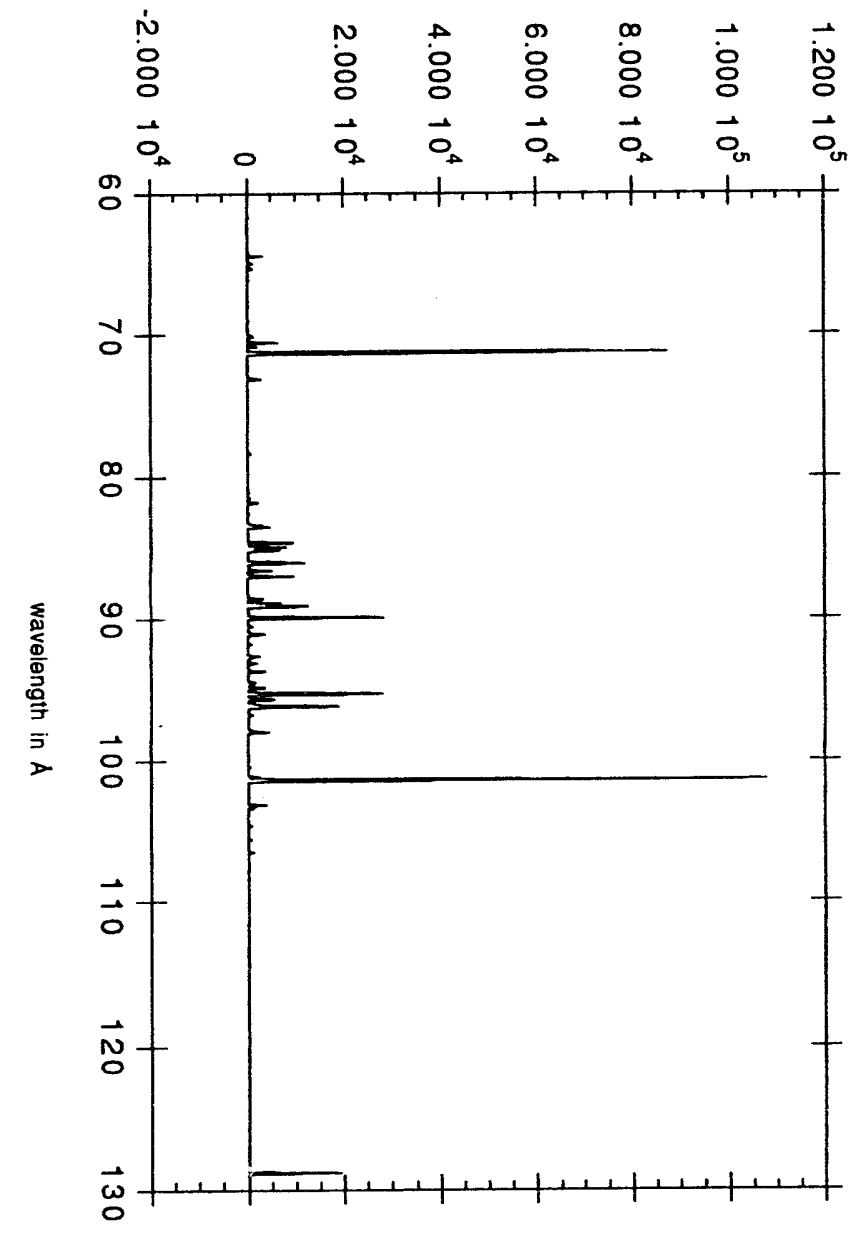

דִ

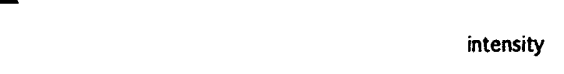

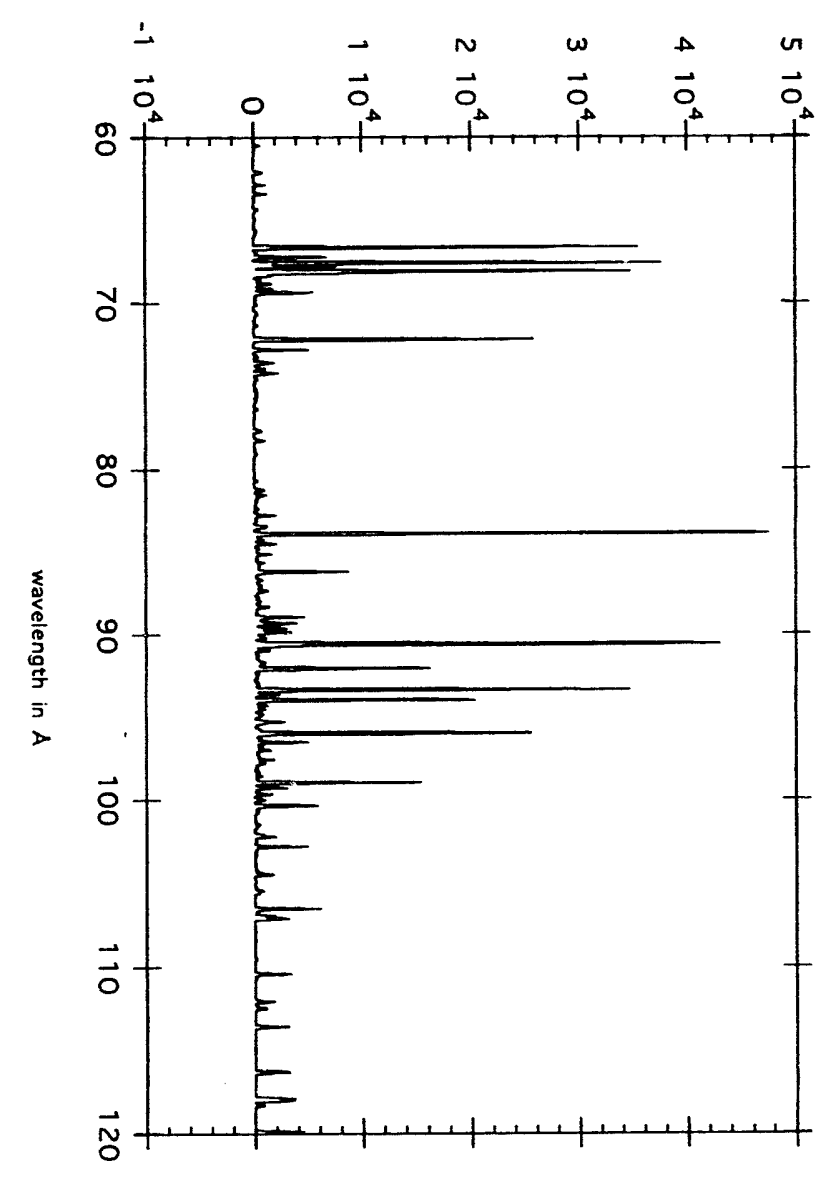




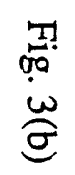

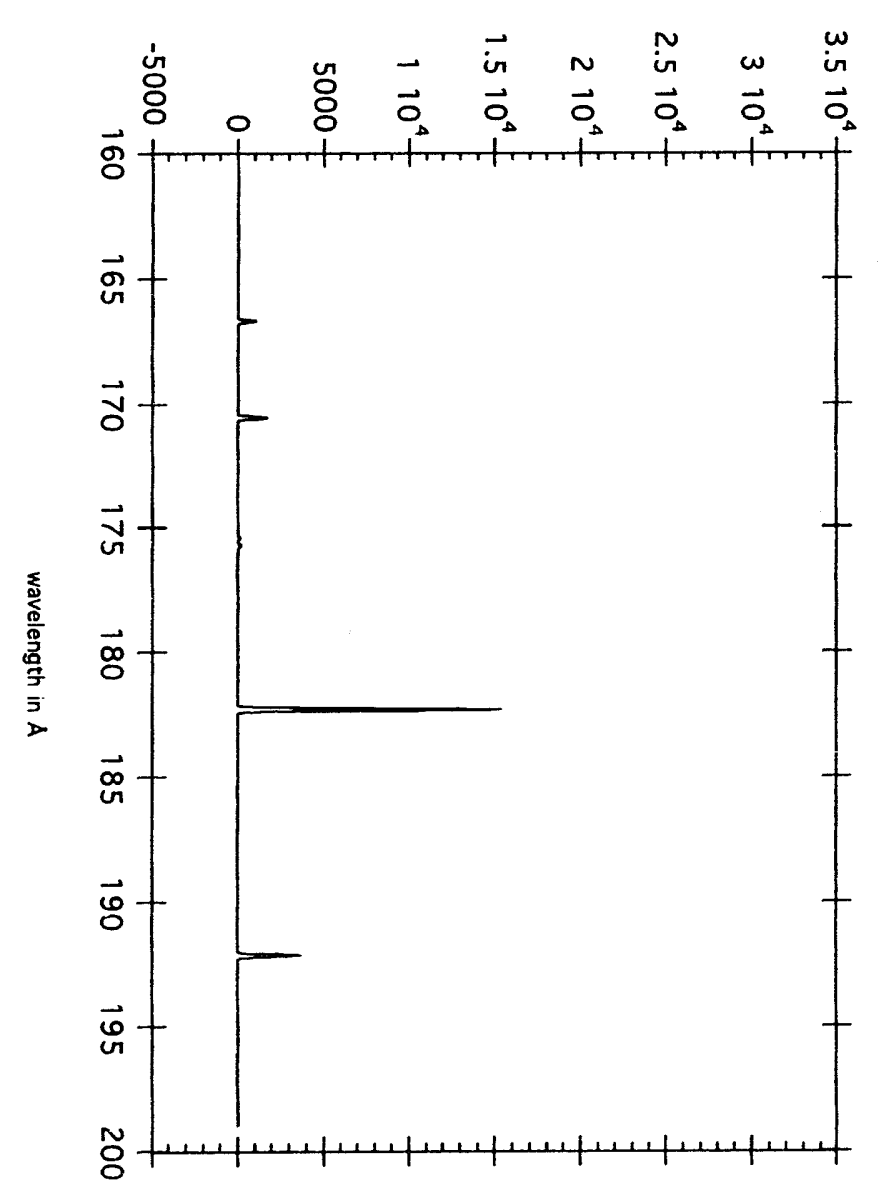

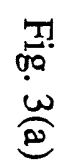

intensity

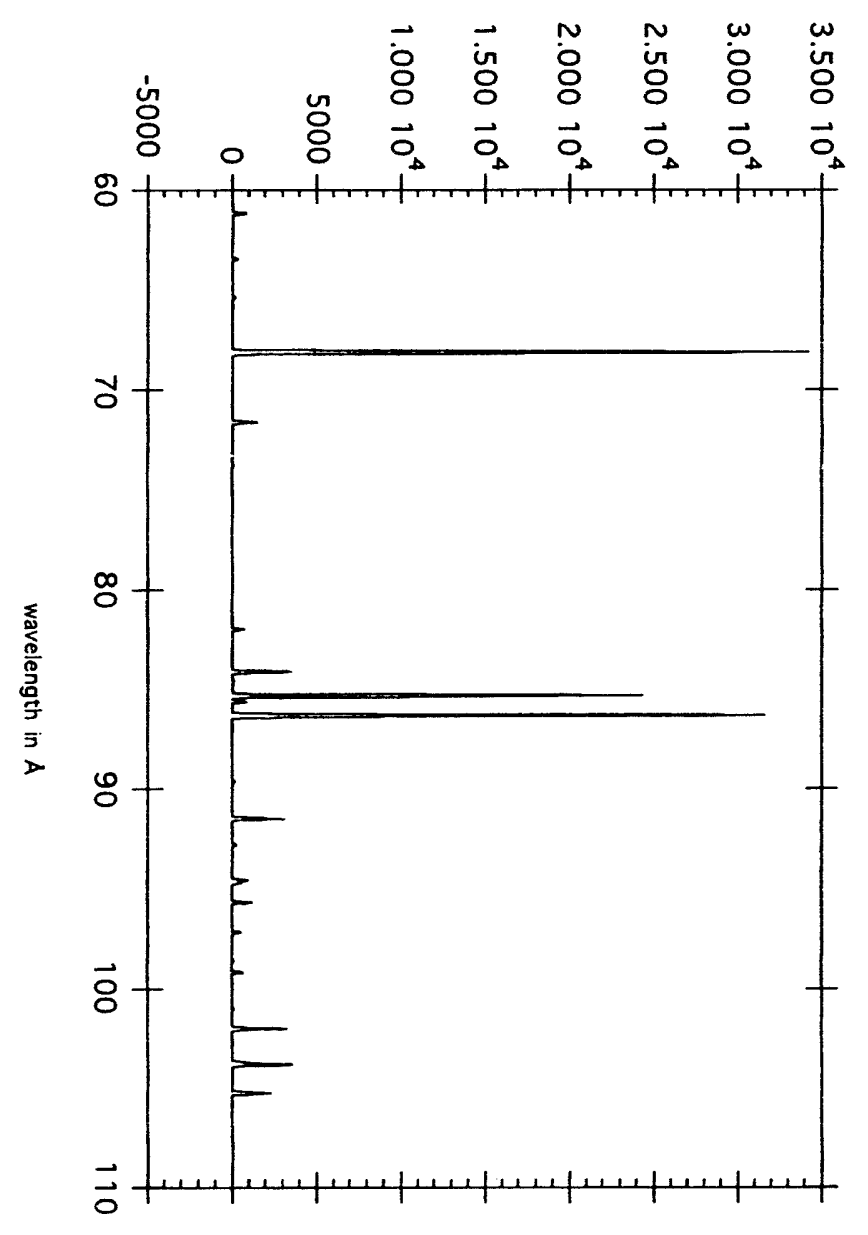



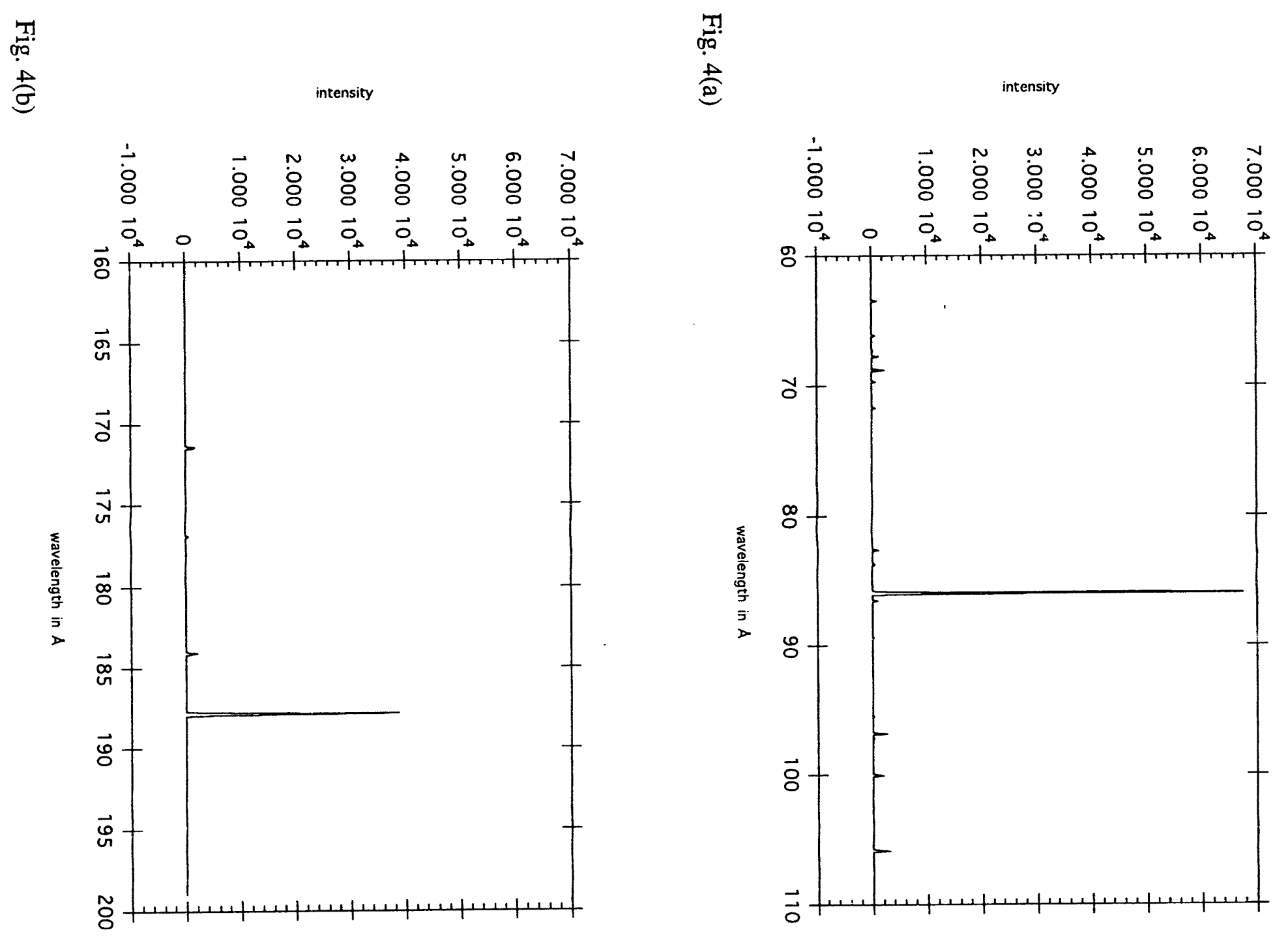

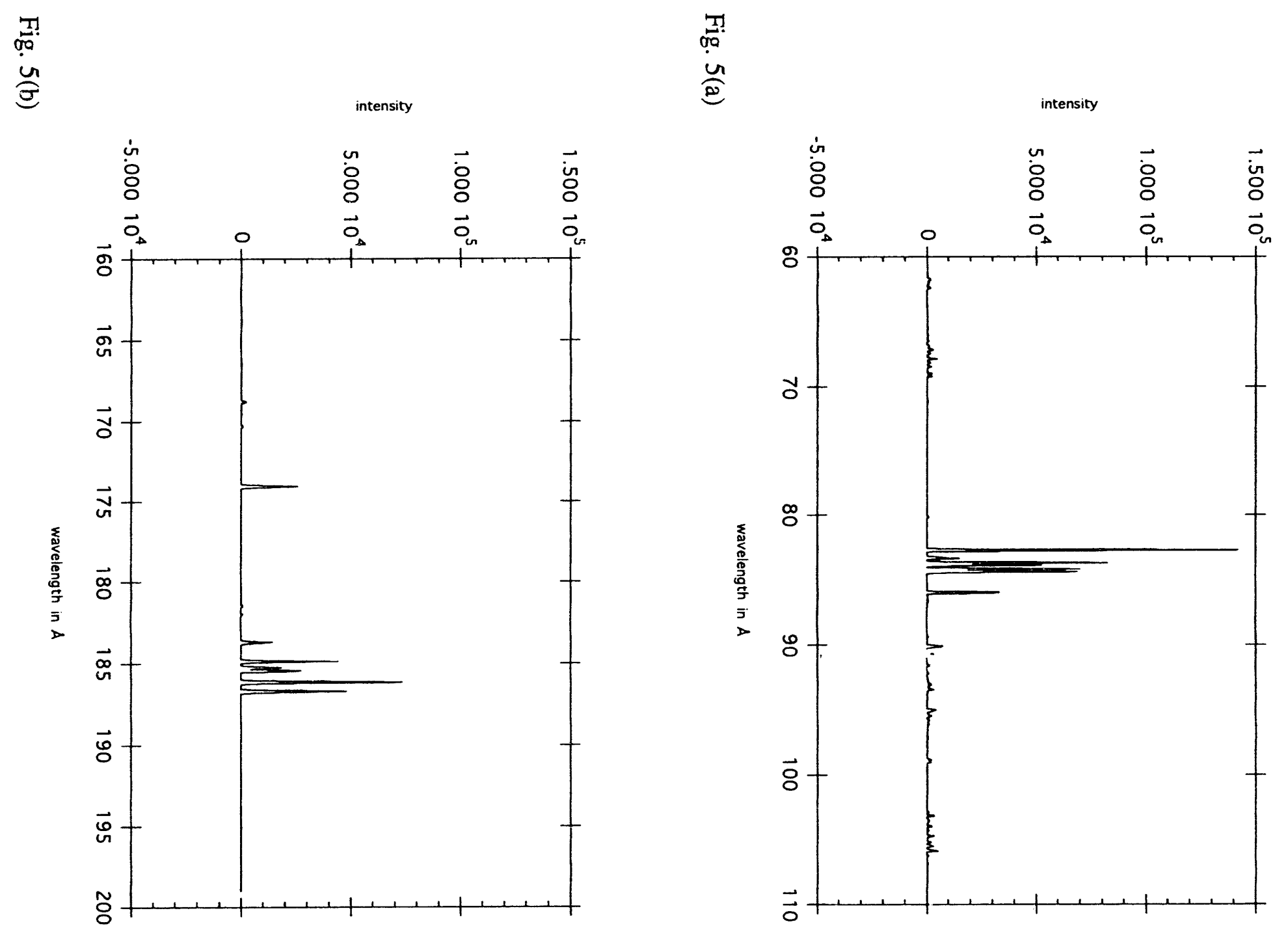

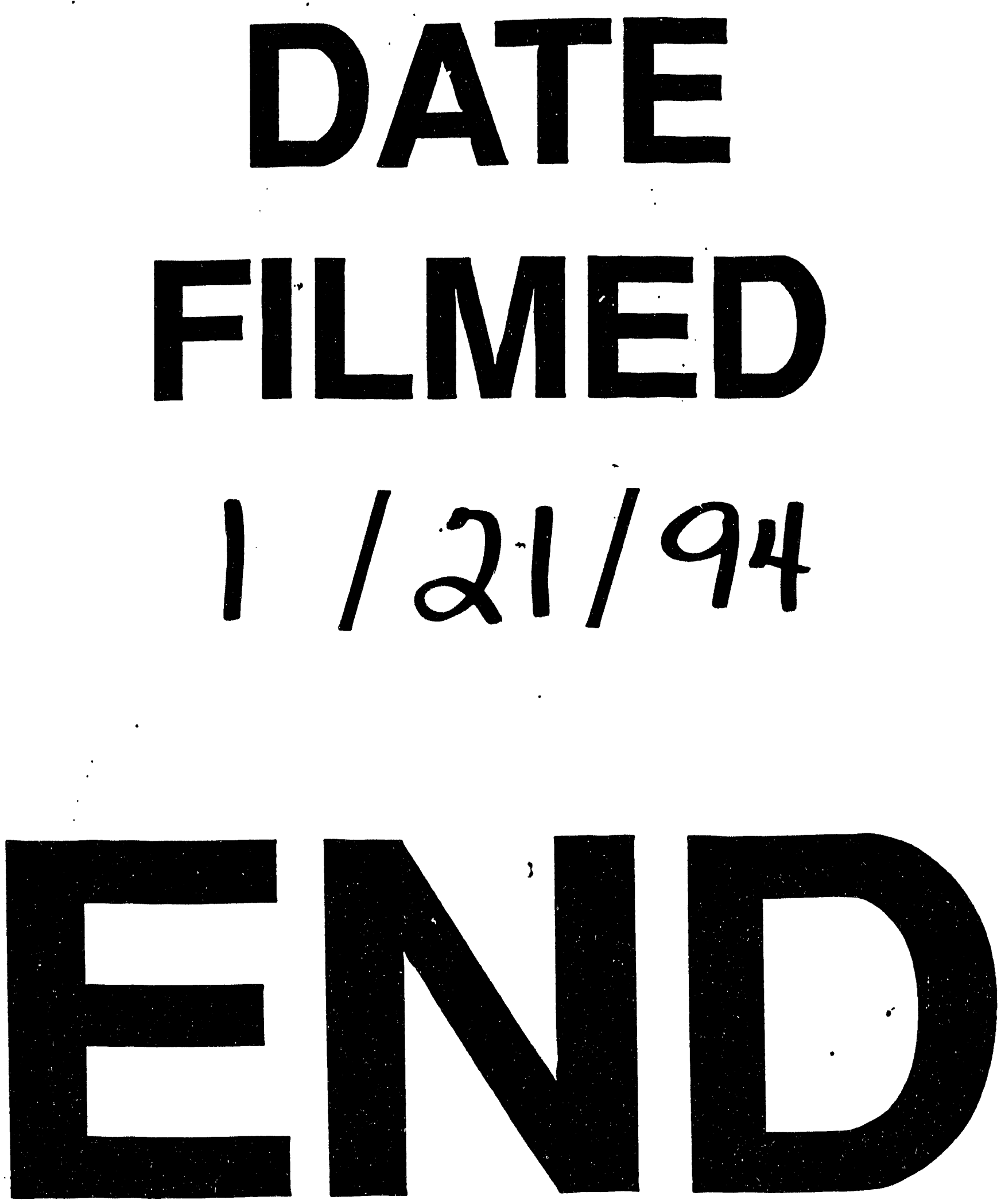
